\title{
Sexual Risk Behavior in HIV-Uninfected Pregnant Women in Western Uganda
}

\author{
Stefanie Theuring ${ }^{1}$ (D) Kenyonyozi Rubagumya ${ }^{2} \cdot$ Hannah Schumann ${ }^{1} \cdot$ Gundel Harms ${ }^{1} \cdot$ John Rubaihayo ${ }^{2}$. \\ Rhoda Wanyenze ${ }^{3}$
}

Received: 13 August 2020 / Revised: 28 March 2021 / Accepted: 25 May 2021 / Published online: 13 October 2021

(c) The Author(s) 2021

\begin{abstract}
Our aim was to identify sexual risk behavior among HIV-negative pregnant women in Kabarole District, Uganda, by conducting a cross-sectional study among 1610 women within three healthcare settings. One in six women engaged in HIV-specific risk behaviors including multiple sexual partners or alcohol abuse; $80 \%$ of the pregnant women reported to generally abstain from using condoms. In multivariate analysis, predictors of sexual risk behavior included being a client of the public health facilities as compared to the private facility (AOR 3.6 and $4.8, p<0.001$ ), being single, widowed or divorced or not cohabiting with the partner (AOR 4.7 and 2.3, $p<0.001$ ), as well as higher household wealth (AOR 1.8, $p<0.001$ ) and lack of partner status knowledge (AOR 1.6, $p=0.008$ ). Self-estimated risk perception was linked with engagement in HIV-related risk behaviors except for alcohol abuse. Our findings indicate that reducing risky behaviors in pregnancy in order to prevent HIV should be a high-priority public health concern.
\end{abstract}

Keywords Sexual risk behavior $\cdot$ HIV risk $\cdot$ Uganda $\cdot$ Pregnancy

\section{Introduction}

While the majority of new HIV infections in Sub-Saharan Africa generally occur in women (UNAIDS, 2020), especially pregnant women may have an elevated risk for HIV incidence compared to the general population (Drake et al., 2014; Kinuthia et al., 2010; Moodley et al., 2009). A study in Rakai, Uganda, revealed 2.3 seroconversions per 100 persons-years in pregnant women compared to 1.1 per 100 person-years in non-pregnant women (Gray et al., 2005). A recent study in Kabarole District, Uganda, showed HIV incidence rates up to 3.0 per 100 women-years in urban and 5.2

Stefanie Theuring

stefanie.theuring@charite.de

1 Institute of Tropical Medicine and International Health, Corporate member of Freie Universität Berlin, Humboldt-Universität Zu Berlin, and Berlin Institute of Health, Charité-Universitätsmedizin, Augustenburger Platz 1, 13353 Berlin, Germany

2 School of Health Sciences, Mountains of the Moon University, Fort Portal, Uganda

3 School of Public Health, Makerere University, Kampala, Uganda per 100 women-years in rural pregnant populations (Schumann et al., 2020). These numbers are particularly worrisome when considering that seroconversion in pregnancy inherits a high risk for vertical transmission, due to a viral load peak during acute infection (Johnson et al., 2012). Assumedly, $43 \%$ of all mother-to-child transmissions are a result of seroconversion during pregnancy or breastfeeding (Johnson et al., 2012). Thus, pregnant women do not only represent a highrisk group for new HIV infections, but also are high-risk vertical transmitters in case of seroconversion.

It is not entirely clear why pregnant women are at increased risk for HIV infection. On the one hand, pregnancy itself may increase the biological susceptibility of a woman for HIV infection through immunological factors or hormonal changes altering genital mucosal surface. On the other hand, pregnant women may have an elevated risk due to specific sociodemographic, sexual and partnership characteristics, potentially influencing their risk for HIV acquisition (Kinuthia et al., 2010). Yet, there is rather limited literature available on sexual risk behavior in pregnancy. A study in South Africa pointed out that $60 \%$ of interviewed pregnant women did not know the HIV status of their partner and an equal rate had not used condoms during the past months; $20 \%$ of the woman in this study reported multiple sex partners in 
the past year (Peltzer \& Mlambo, 2013). Several other studies reported accordingly that condom use was less frequent in pregnant women. (Gray et al., 2005; Jones et al., 2011; Keating et al., 2012). This might be a result of omitting condoms as a purely contraceptive method without considering prevention of sexually transmitted diseases including HIV (Peltzer \& Mlambo, 2013), possibly also linked with a weaker condom-negotiating position of the woman toward the partner or husband based on this rationale. Overall, while mechanisms for HIV-positive pregnant women to prevent vertical transmission have received a lot of attention in the past decades, primary prevention among those antenatal care (ANC) clients tested HIV-negative has largely remained out of focus. Offering repeat testing during pregnancy, as it is recommended in many countries including Uganda (Uganda MoH, 2016), will help identify some seroconverted women, but is not primarily contributing to HIV prevention in pregnancy.

In order to inform and guide effective prevention interventions, it is crucial that we gain better understanding of behavioral specificities in pregnancy potentially influencing the risk for HIV seroconversion. Hence, the aim of this study was to shed light on sexual risk behavior of HIV-negative women during pregnancy and factors associated with this behavior, in order to be able to tailor HIV prevention programs fitting specific needs of this vulnerable population group. Our study was located in Kabarole District, Western Uganda, an area highly affected by the HIV epidemic (Rubaihayo et al., 2010; Uganda AIDS Commission, 2016). HIV-positive pregnant women in Kabarole District receive care and treatment following a well-established health service algorithm including Option B+, i.e., lifelong antiretroviral therapy (Schnack et al., 2016), but similar to the larger global picture, in this setting, ANC clients also largely drop out of the focus of HIVrelated attention as soon as tested HIV-negative.

\section{Method}

Within the larger frame of a cross-sectional study on HIV incidence among pregnant women in Western Uganda (Schumann et al., 2020), we performed a retrospective assessment of sexual risk behavior among HIV-negative women during their current pregnancy. Primary outcome parameter was the prevalence of risk behavior in pregnant women. Secondary outcome parameters were sociodemographic and economic predictors for sexual risk behavior and the linkage between women's own risk perception and risk behavior.

\section{Study Setting}

The study was located in the rural setting of Kabarole District, which has an estimated population of 450,000. Despite considerable efforts, HIV remains a major problem in this district, with Fort Portal Municipality belonging to one of the most HIV-affected areas in Uganda (Rubaihayo et al., 2010). In previous studies, HIV prevalence in pregnant women in Fort Portal, the district capital, was found to be about $10 \%$ in 2013 (Schnack et al., 2016). Three hospitals in Fort Portal serve the population in Kabarole District, in addition to approximately 40 further health centers level I-IV (Uganda Bureau of Statistics, 2016).

Our research sites included the Regional Referral Hospital Fort Portal, also known as Buhinga, the private catholic Holy Family Virika Hospital in Fort Portal, and Kibiito Health Center IV in a rural area $30 \mathrm{~km}$ south of Fort Portal. The three hospitals were selected purposively using a maximum variation approach (Palinkas et al., 2015) and are covering differences in scope (governmental/private, level of care) and facility size. Virika and Kibiito each attend to around 100, Buhinga to around 250 new ANC clients per month. All three sites offer standard ANC services, obstetric care, postpartum care and HIV care free of charge. ANC clients are tested for HIV at first ANC encounter and enrolled in PMTCT services if HIV-positive. If HIV-negative, they are re-tested after three months according to the national and WHO guidelines (WHO, 2010). None of the three facilities offered specific HIV education or other prevention interventions for HIVnegative pregnant women at the time of the study.

\section{Participants and Procedure}

Recruitment of study participants took place in ANC and maternity wards of the three facilities. Through this, we aimed at enrolling as many women as possible within the recruitment period, including those only attending ANC, but not delivering in hospital, as well as those not attending more than one ANC visit or attending ANC elsewhere, but delivering at the study sites. This recruitment strategy was designed to help avoiding selection bias associated with facility-based deliveries or with ANC late-presenters. Data collection took place between June and November 2017. At each of the three study sites, there was one nurse in charge of the study who had been trained in study procedures and who instructed other staff.

General eligibility criteria included existing pregnancy with being in the third gestational trimester or early postdelivery stage while still being hospitalized after giving birth, and having tested HIV-negative at the first ANC visit in this pregnancy. Including women at $\geq 28$ gestational weeks ensured to cover a sufficiently large period of pregnancy when asking about sexual risk behavior. Other eligibility criteria were age of 15 years (emancipated minors; Uganda National Council for Science and Technology, 2014) or above and written informed consent to participate in the study. Women were recruited into the study subsequently to their routine health care (ANC or delivery-related). 


\section{Measures}

After obtaining informed consent, a study nurse conducted an interview based on a structured questionnaire on sociodemographic factors, like age, education and marital status, as well as behavioral information, such as number of sexual partners, use of condoms, or alcohol abuse. In addition, women were asked to self-assess their perceived risk for acquiring HIV infection in four categories from "high risk" to "not at risk." For evaluating their socioeconomic status (SES), participants reported the availability of certain items within the household, including radio, fridge, a motorbike or car, electricity, tap water, a cupboard, TV, cattle and a mosquito net, resulting in a wealth score ranging from $0-9$.

From the behavioral variables reported in the interviews, we built a dichotomous category for presence or absence of risk behavior in pregnancy, with any one of the following variables leading to inclusion in the "risk behavior" group: two or more sexual partners; at least one incidence of unprotected sex with an unknown person; alcohol abuse (i.e., habit of repeated excessive alcohol drinking); at least one incidence of sex under the influence of drugs or alcohol. These variables were chosen because they were independent predictors of HIV seroconversion in pregnancy in preceding data analysis within the same cohort (Schumann et al., 2020), they also comply with variables defining the "at-risk" group in other research (Palomino González et al., 2019). The study nurses asked for engagement in the respective behaviors since the start of 2017, hence, covering six months at the onset of data collection in June. Additionally, study nurses probed women specifically as to engagement in those behaviors during pregnancy. In addition to the dichotomous risk behavior category, we also built a risk behavior score ranging from $0-4$ according to the number of risk behaviors a person reported.

\section{Data Analysis}

A descriptive analysis was performed, calculating frequencies and percentages for the total cohort as well as for the three health facilities. In bivariate analysis, we identified significant associations of sociodemographic characteristics with engagement in risk behavior using Pearson's chi-square test. $p$-levels below 0.05 were considered as statistically significant. To adjust for potential confounders, we performed multivariate analysis on those factors showing significance in bivariate analysis. For this purpose, we used a binary logistic regression model based on the dichotomous risk behavior category and compared this with results of an ordered logistic regression model based on the risk behavior score. For both models, we report adjusted odds ratios and $95 \%$ confidence intervals. To test the association between own risk perception regarding HIV acquisition and the risk behavior score, we used a chi-square-contingency table. To assess the link of sexual risk behaviors and perceived risk to acquire HIV, we calculated adjusted odds ratios using ordered logistic regression.

\section{Results}

From the recruited 1610 clients, 703 (43.7\%) were from the public Buhinga Hospital, 408 (25.3\%) from the rural Kibiito Health Center, and 499 (31.0\%) from the private Virika Hospital. Altogether, 884 (55\%) women were recruited in ANC and 726 in the maternity ward. Sociodemographic as well as risk-behavioral parameters in the three different facilities are indicated in Table 1 . The majority $(55.7 \%)$ of participants were younger than 25 years. Only $14 \%$ did not have a partner, but about half of the woman in marriage or a relationship were not permanently cohabiting with their partner. Almost two-thirds estimated their own risk for HIV acquisition as very low or nonexistent. About $18 \%$ of all participants stated not to know their partner's HIV status. About $72 \%$ stated to be sexually active at this point. Almost $80 \%$ of all clients reported that they would generally never use condoms.

Among our risk-behavior categories, $15.3 \%$ of all women stated they had two or more sexual partners in the current year, $5.7 \%$ reported alcohol abuse, 2.9\% said they had at least one incidence of unprotected sex with an unknown person, and $1 \%$ stated that they had had sex under the influence of drugs or alcohol. From all 1610 participants, $269(16.7 \%)$ reported to engage in at least one behavior category implicating risk of HIV acquisition; onethird of these $(n=89)$ were involved in two or more risky behavior categories.

\section{Association of Sociodemographic Characteristics with Reported Risk Behavior}

Bivariate analysis (Table 2) showed significant differences between women who engaged in HIV risk behavior and women who did not, related to their age group, marital status, wealth category, and knowledge on partner status. While among clients of the large urban public Buhinga Hospital, 25.0\% reported to engage in risk behavior, this applied to $14.1 \%$ in the rural public Kibiito HC, and only to $6.6 \%$ in the private, catholic Virika Hospital.

In accordance, both logistic regression models (Table 3) identified the following factors to be independent predictors of engagement in HIV risk behavior: being a client at Buhinga or Kibiito; living in a non-cohabiting relationship or being single, widowed or divorced; reporting a higher wealth score; and reporting unknown partner status. Age 
Table 1 The sociodemographic characteristics, risk perception, and risk behavior of the study participants

\begin{tabular}{|c|c|c|c|c|}
\hline Variable & $\begin{array}{l}\text { Total } \\
n(\%)\end{array}$ & Buhinga (urban public) & Kibiito (rural public) & Virika (urban private) \\
\hline Total study population $(n=1610)$ & $1610(100)$ & 703 (43.66) & $408(25.34)$ & $499(30.99)$ \\
\hline \multicolumn{5}{|l|}{ Age groups $(n=1604)$} \\
\hline $15-24$ years of age & $893(55.7)$ & $427(60.9)$ & $240(59.3)$ & $226(45.4)$ \\
\hline $25-34$ years of age & $580(36.2)$ & $226(32.3)$ & $131(32.4)$ & $223(44.8)$ \\
\hline $35-50$ years of age & $131(8.17)$ & $48(6.9)$ & $34(8.4)$ & $49(9.8)$ \\
\hline \multicolumn{5}{|l|}{ Marital status $(n=1608)$} \\
\hline Married or cohabiting & $625(38.9)$ & $222(31.6)$ & $229(56.1)$ & $174(34.9)$ \\
\hline Non-cohabiting couple & 754 (46.9) & $346(49.3)$ & $132(32.4)$ & $276(55.4)$ \\
\hline Single, widowed or divorced & $229(14.2)$ & $134(19.1)$ & $47(11.5)$ & $48(9.6)$ \\
\hline \multicolumn{5}{|l|}{ Education $(n=1606)$} \\
\hline Primary or less & $848(52.8)$ & $391(55.7)$ & $281(69.0)$ & $176(35.4)$ \\
\hline Secondary or more & $758(47.2)$ & $311(44.3)$ & $126(31.0)$ & $321(64.6)$ \\
\hline \multicolumn{5}{|l|}{ Wealth score $(n=1610)$} \\
\hline $0-3$ & $574(35.7)$ & $218(31.0)$ & $240(58.8)$ & $116(23.3)$ \\
\hline $4-9$ & $1036(64.4)$ & $485(69.0)$ & $168(41.2)$ & $383(76.8)$ \\
\hline \multicolumn{5}{|l|}{ Partner age $(n=1597)$} \\
\hline $14-24$ years of age & 341 (21.4) & $163(23.5)$ & $103(25.3)$ & 75 (15.2) \\
\hline $25-34$ years of age & 794 (49.7) & $348(50.1)$ & $201(49.4)$ & $245(49.5)$ \\
\hline $35-60$ years of age & $462(28.9)$ & $184(26.5)$ & $103(25.3)$ & $175(35.4)$ \\
\hline \multicolumn{5}{|l|}{ Partner education $(n=1590)$} \\
\hline Primary or less & $643(40.4)$ & $268(38.8)$ & $242(59.6)$ & $133(26.9)$ \\
\hline Secondary or more & 947 (59.6) & $422(61.2)$ & $164(40.4)$ & $361(73.1)$ \\
\hline \multicolumn{5}{|l|}{ Own HIV risk perception $(n=1608)$} \\
\hline High & $131(8.2)$ & $53(7.5)$ & $49(12.0)$ & $29(5.8)$ \\
\hline Some & $419(26.1)$ & $205(29.2)$ & $111(27.3)$ & $103(20.7)$ \\
\hline Very low & $396(24.6)$ & $242(34.4)$ & $38(9.3)$ & $116(23.3)$ \\
\hline Not at risk & $662(41.2)$ & 203 (28.9) & $209(51.4)$ & $250(50.2)$ \\
\hline \multicolumn{5}{|c|}{ No. of sexual partners in the ongoing year $(n=1578)$} \\
\hline One or less & $1337(84.7)$ & $528(76.4)$ & $352(88.2)$ & 457 (93.7) \\
\hline Two or more & $241(15.3)$ & $163(23.6)$ & $47(11.8)$ & $31(6.4)$ \\
\hline \multicolumn{5}{|c|}{ Unprotected sex with unknown person $(n=1610)$} \\
\hline Yes & $46(2.9)$ & $26(3.7)$ & $16(3.9)$ & $4(0.8)$ \\
\hline No & $1564(97.1)$ & $677(96.3)$ & $392(96.1)$ & $495(99.2)$ \\
\hline \multicolumn{5}{|l|}{ Alcohol abuse $(n=1610)$} \\
\hline Yes & $92(5.7)$ & $69(9.8)$ & $19(4.7)$ & $4(0.8)$ \\
\hline No & $1518(94.3)$ & $634(90.2)$ & $389(95.3)$ & $495(99.2)$ \\
\hline \multicolumn{5}{|c|}{ Sex under influence of drugs or alcohol $(n=1610)$} \\
\hline Yes & $17(1.1)$ & $7(1.0)$ & $10(2.5)$ & 0 \\
\hline No & $1593(98.9)$ & $696(99.0)$ & $398(97.6)$ & $499(100.0)$ \\
\hline \multicolumn{5}{|c|}{ HIV Status of partner known $(n=1607)$} \\
\hline Yes & $1318(82.0)$ & $576(82.1)$ & $304(74.7)$ & $438(88.0)$ \\
\hline No & $289(18.0)$ & $126(18.0)$ & $103(25.3)$ & $60(12.1)$ \\
\hline \multicolumn{5}{|l|}{ Currently sexually active $(n=1604)$} \\
\hline Yes & $1154(72.0)$ & $534(76.0)$ & $243(59.7)$ & $377(76.3)$ \\
\hline No & $450(28.1)$ & $169(24.0)$ & $164(40.3)$ & $117(23.7)$ \\
\hline \multicolumn{5}{|c|}{ Condom use when sexually active $(n=1571)$} \\
\hline Always & $22(1.4)$ & $7(1.0)$ & $8(2.0)$ & $7(1.4)$ \\
\hline Sometimes & $144(9.2)$ & $61(8.9)$ & $49(12.2)$ & $34(7.0)$ \\
\hline Rarely & $150(9.6)$ & $84(12.3)$ & $18(4.5)$ & $48(9.9)$ \\
\hline
\end{tabular}


Table 1 (continued)

\begin{tabular}{lllll}
\hline Variable & $\begin{array}{l}\text { Total } \\
n(\%)\end{array}$ & Buhinga (urban public) & Kibiito (rural public) & Virika (urban private) \\
\hline Never & $1255(79.9)$ & $532(77.8)$ & $327(81.3)$ & $396(81.7)$ \\
\hline
\end{tabular}

Table 2 Association of sociodemographic characteristics with reported risk behavior

\begin{tabular}{|c|c|c|c|}
\hline Variable & $\begin{array}{l}\text { Participants reporting } \\
\text { risk behavior }^{\mathrm{a}}\end{array}$ & $\begin{array}{l}\text { Participants reporting no } \\
\text { risk behavior }\end{array}$ & $p$ value $^{\mathrm{b}}$ \\
\hline Total study population $(n=1610)$ & $269(16.7 \%)$ & $1341(83.3 \%)$ & - \\
\hline \multicolumn{4}{|l|}{ Age group $(n=1604)$} \\
\hline $15-24$ years of age & $173(19.4 \%)$ & $720(80.6 \%)$ & \multirow{3}{*}{0.003} \\
\hline $25-34$ years of age & $84(14.5 \%)$ & $496(85.5 \%)$ & \\
\hline $35-50$ years of age & $12(9.2 \%)$ & $119(90.8 \%)$ & \\
\hline \multicolumn{4}{|l|}{ Facility $(n=1610)$} \\
\hline Buhinga (urban public) & $176(25.0 \%)$ & $527(75.0 \%)$ & \multirow{3}{*}{$<0.001$} \\
\hline Kibiito (rural public) & $60(14.1 \%)$ & $348(85.9 \%)$ & \\
\hline Virika (urban private) & $33(6.6 \%)$ & $466(93.4 \%)$ & \\
\hline \multicolumn{4}{|l|}{ Marital status $(n=1608)$} \\
\hline Married or cohabiting & $58(9.3 \%)$ & $567(90.7 \%)$ & \multirow{3}{*}{$<0.001$} \\
\hline Non-cohabiting couple & $133(17.6 \%)$ & $621(82.4 \%)$ & \\
\hline Single, widowed or divorced & $78(34.1 \%)$ & $151(65.9 \%)$ & \\
\hline \multicolumn{4}{|l|}{ Education $(n=1606)$} \\
\hline Primary or less & $141(16.6 \%)$ & $707(83.4 \%)$ & \multirow[t]{2}{*}{0.890} \\
\hline Secondary or more & $128(16.9 \%)$ & $630(83.1 \%)$ & \\
\hline \multicolumn{4}{|l|}{ Wealth score $(n=1610)$} \\
\hline $0-3$ & $77(13.4 \%)$ & $497(86.6 \%)$ & \multirow[t]{2}{*}{0.008} \\
\hline $4-9$ & $192(18.5 \%)$ & $844(81.5 \%)$ & \\
\hline \multicolumn{4}{|l|}{ Partner HIV status $(n=1607)$} \\
\hline Known & $196(14.9 \%)$ & $1122(85.1 \%)$ & \multirow[t]{2}{*}{$<0.001$} \\
\hline Unknown & $73(25.3 \%)$ & $216(74.7 \%)$ & \\
\hline \multicolumn{4}{|l|}{ Partner age $(n=1597)$} \\
\hline $14-24$ years of age & $62(18.2 \%)$ & $279(81.8 \%)$ & \multirow{3}{*}{0.100} \\
\hline $25-34$ years of age & $140(17.6 \%)$ & $654(82.4 \%)$ & \\
\hline $35-60$ years of age & $62(13.0 \%)$ & $400(87.0 \%)$ & \\
\hline \multicolumn{4}{|l|}{ Partner education $(n=1590)$} \\
\hline Primary or less & $99(15.4 \%)$ & $544(84.6 \%)$ & \multirow[t]{2}{*}{0.396} \\
\hline Secondary or more & $161(17.0 \%)$ & $786(83.0 \%)$ & \\
\hline
\end{tabular}

${ }^{a}$ Risk behavior is defined as mentioning of at least one of the following behaviors in the ongoing year, i.e., during pregnancy: number of sexual partners $>1$, unprotected sex with unknown persons, alcohol abuse and sex under the influence of drugs or alcohol

${ }^{\mathrm{b}}$ Pearson's chi-square test was no longer a statistically significant influencing factor of risk behavior in multivariate analysis. ANC clients attending Buhinga and Kibiito were about 4 times more likely to report risk behavior compared to clients attending Virika Hospital. Women being single, widowed or divorced were at almost fivefold risk of reporting risk behavior engagement, while women who were in a partnership, but not permanently cohabiting with their partner still were twice as likely to engage in risk behavior compared to women living with their partner. 
Table 3 Association of sociodemographic characteristics with sexual risk behavior during pregnancy: Logistic regression models ${ }^{\mathrm{a}}$

\begin{tabular}{|c|c|c|}
\hline \multirow[t]{2}{*}{ Variable } & $\begin{array}{l}\text { Model 1: Logistic regression Risk behavior } \\
\text { as binary variable }\left(n=1569^{\mathrm{b}}\right)\end{array}$ & $\begin{array}{l}\text { Model 2: Ordered logistic regres- } \\
\text { sion Risk behavior as ordinal variable } \\
\left(n=1569^{\mathrm{b}}\right)\end{array}$ \\
\hline & \multicolumn{2}{|l|}{ AOR $(95 \% \mathrm{CI}), p$ value } \\
\hline \multicolumn{3}{|l|}{ Facility $^{\mathrm{d}}$} \\
\hline Virika (reference) & - & - \\
\hline Kibiito & $3.600(2.212-5.860),<0.001$ & $3.794(2.331-6.173),<0.001$ \\
\hline Buhinga & $4.747(3.157-7.138),<0.001$ & $4.921(3.272-7.400),<0.001$ \\
\hline $\operatorname{Age}^{c d}$ & 1.005 (0.980-1.032), 0.690 & $1.011(0.985-1.037), 0.404$ \\
\hline \multicolumn{3}{|l|}{ Marital status $^{\mathrm{d}}$} \\
\hline Married or cohabiting (reference) & - & - \\
\hline Non-cohabiting couple & $2.304(1.629-3.258),<0.001$ & $2.441(1.727-3.451),<0.001$ \\
\hline Single, widowed or divorced & $4.654(3.006-7.207),<0.001$ & $5.042(3.269-7.779),<0.001$ \\
\hline \multicolumn{3}{|l|}{ Education $^{\mathrm{d}}$} \\
\hline Primary or less (reference) & - & - \\
\hline Secondary or more & $1.023(0.756-1.383), 0.884$ & 1.007 (0.748-1.357), 0.961 \\
\hline Wealth score ${ }^{c d}$ & $1.188(1.096-1.289),<0.001$ & $1.196(1.103-1.296),<0.001$ \\
\hline \multicolumn{3}{|l|}{ Partner HIV status ${ }^{\mathrm{d}}$} \\
\hline Known (reference) & - & - \\
\hline Unknown & 1.594 (1.129-2.252), 0.008 & 1.655 (1.180-2.321), 0.004 \\
\hline Overall model pseudo-R-squared value, $p$-value & $0.1115,<0.001$ & $0.0888,<0.001$ \\
\hline Pearson goodness-of-fit test: Estimate, $p$-value & $1214.86,0.0559^{\mathrm{e}}$ & - \\
\hline Hosmer-Lemeshow test: Estimate, $p$-value & - & $31.341,0.6455^{\mathrm{e}}$ \\
\hline
\end{tabular}

${ }^{a}$ Four risk factors for HIV incidence in pregnancy (number of sexual partners $>1$, unprotected sex with unknown persons, alcohol abuse, and sex under influence of drugs or alcohol) were evaluated using two scoring systems, a binary and an ordinal one. The binary score included two values, where $0=$ participant reporting no risk behavior and $1=$ participant reporting one risk behavior or more; the ordinal score included five ordinal values, where $0=$ participant reporting no risk behavior and $4=$ participant reporting all four risk behaviors

${ }^{\mathrm{b}}$ Observations with missing values were excluded in the two regression models

${ }^{\mathrm{c}}$ Continuous variable

${ }^{\mathrm{d}}$ The two models are showing matching results

${ }^{\mathrm{e}} p$ value is showing the model to be a good fit

OR: odds ratio

CI: confidence interval

Fig. 1 Sexual risk behavior score and own perceived risk of acquiring HIV. Pearson's chisquare $p<0.001$

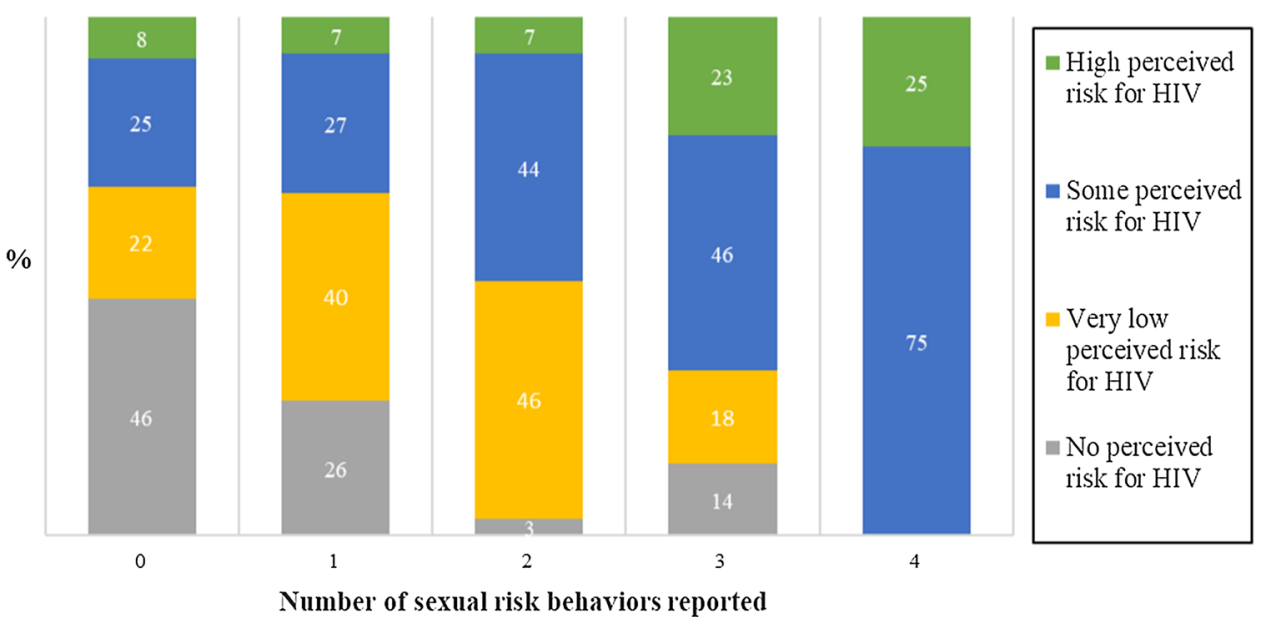


Table 4 Association of participants' own HIV risk perception with their sexual risk behaviors, ordered logistic regression

\begin{tabular}{ll}
\hline Risk Behavior & $\begin{array}{l}\text { Own risk perception, ordered } \\
\text { scale AOR }(95 \% \text { CI), } p \text { value }\end{array}$ \\
\hline Alcohol abuse & $1.474(0.969-2.241), 0.070$ \\
Unprotected sex with unknown person & $2.232(1.192-4.180), 0.012$ \\
Sex under influence of drugs or alcohol & $2.882(1.126-7.376), 0.027$ \\
Number of sexual partners $>1$ & $1.440(1.104-1.880), 0.007$ \\
Overall model pseudo-R-squared value, $p$ value & $0.0139,<0.001$ \\
\hline
\end{tabular}

\section{Own Risk Perception of HIV Acquisition and Risk Behavior}

The level of study participants' self-perception of HIV risk was significantly linked to the number of risk behaviors a person engaged in (Fig. 1). When analyzing independent influence of four different HIV risk behavior variables on the level of own risk perception, we found that sex under the influence of drugs or alcohol, unprotected sex with unknown persons, and two or more sexual partners in the ongoing year were independently associated with an increased risk perception on a statistically significant level. Alcohol abuse was the only factor not significantly associated with risk perception (see Table 4 and Fig. 1).

\section{Discussion}

Within a large sample of HIV-negative pregnant women, our research assessed HIV-related risk behavior and identified groups of women particularly prone to high-risk behavior. While almost one in five women stated that her partner's HIV status was unknown to her, the vast majority of our sample also reported to generally not use condoms. Overall, one in six pregnant women reported engagement in at least one risklinked behavior in pregnancy.

As anticipated prior to selecting the study sites, the three different health settings showed differences in the clientele characteristics and in behaviors. Clients at the public, governmental facilities were about four times as likely to engage in risk behavior as compared to the private hospital. A Kenyan study on urban and rural differences in sexual risk behavior (Dodoo et al., 2007) found that within the subgroup of poorer clients, urban poor population was significantly more prone to risky sexual behaviors than rural poor population. Assuming that public facility clients are usually poorer than private facility clients, as also mirrored in the wealth score distribution in our cohort, this precisely reflects findings in our three facilities: "urban poor" clientele in Buhinga was much more engaged in risk behavior (25\%) than "rural poor" clientele in Kibiito (14\%), while least risk behavior was displayed in the private facility Virika (7\%). This is a highly relevant mesolevel finding for prevention service implementers, implying that especially in public facilities and in rural areas, where pregnant women also tend to be younger and less educated, the focus on risk behavior information and prevention measures should be strongly sharpened. In terms of cost-effectiveness, systematically targeting entire healthcare settings which are known for vulnerable clientele could have implementation advantages over identification of individual at-risk clients at such facilities.

The fact that women who did not know their partner's status were showing more risk behavior could be a result of an underlying factor of general carelessness or lack of health education in this group. Women's marital and cohabiting status was also a significant predictor of risk behavior engagement. Women in a partnership, but not permanently living with their partner, as well as the single, divorced, or widowed were at double, respectively, fivefold increased risk for potentially harmful sexual behavior. Widows and divorced women have been described as particularly vulnerable for HIV in previous research in several African countries (Abimanyi-Ochom, 2011; Tenkorang, 2014), which can partly be explained by financial hardship and sexually exploitative societal customs this group of population is confronted with, for instance, in the case of widow inheritance by other family members. A conscientious health policy response needs to protect women from exposure to such detrimental conventions. Our findings also support research results from Thailand, where among a sample of factory workers, risk behavior was fivefold higher in those not cohabiting with a partner (Hong \& Thepthien, 2017), probably because of the lack of social control when the partner is away from home. The Thai study also found an effect from alcohol abuse, increasing risk behavior especially among those not cohabiting with a partner.

On a micro-level, as opposed to the aforementioned mesolevel of healthcare settings, a higher wealth score in individual persons turned out to be a predictor of HIV risk behavior. For a long time, it was contrarily argued that poverty is the main underlying factor of HIV risk (Fenton, 2004). This was undermined by several studies stating that, somewhat counterintuitively, household wealth can in fact be strongly associated with HIV prevalence (Abimanyi-Ochom, 2011; Parkhurst, 2010; Shelton et al., 2005) possibly by simply enabling someone to have more sexual partners. While those studies looked at HIV prevalence and could not exclude a 
bias of wealthier people with HIV potentially living longer than less wealthy people, hence showing higher prevalence rates, the findings of our study support the recognition that wealthier individuals within all different types of institutional settings actually are more likely to engage in risk behavior. Shelton et al. (2005) argued that wealth is an important prerequisite for social networks, mobility and time, all of which are key enablers for having concurrent partnerships, and they point out that this connection was even stronger in women than in men in data from East Africa. We argue that higher wealth might also enable individuals to excessively consume alcohol; however, these two factors were not associated on a significant level in our study.

Despite the fact that general discouragement of alcohol consumption in pregnancy is taking place in antenatal counseling because of the teratogenic effect on the fetus, in our sample, alcohol abuse was present to some extent, reaching $10 \%$ in the urban public health facility. Those rates may still be an underestimate caused by social desirability bias. Other studies have equally observed high acceptability of alcohol consumption during pregnancy in Sub-Saharan African countries (Mpelo et al., 2018; Watt et al., 2014). Watt et al. described alcohol as a coping strategy with stressors during pregnancy, but also as a way to maintain social connections during this time. Interestingly, in the context of HIV risk awareness, reported alcohol abuse was the only risk factor that was not leading to a higher self-awareness of individual risk for HIV in our study participants. While there might be a general societal problem of sufficient consciousness of risks emerging from alcohol consumption in pregnancy (CorralesGutierrez et al., 2019), this finding implies that there might be a particular lack of knowledge on the potentially harmful outcomes of impaired sexual decision-making after alcohol consumption. Health service implementers should direct more attention to the problem of alcohol drinking during pregnancy, creating alertness not only regarding detrimental effects on the unborn, but also regarding the associated risk for a woman to get infected with HIV. Since alcohol consumption is a behavior deeply rooted within societies and cultures, approaches to target this matter should not focus on health facilities alone, but also on other public sceneries like bars and alcohol-serving settings, which might offer important opportunities to identify and counsel women at risk of drinking during pregnancy (Watt et al., 2014). Overall, the HIV risk self-perception in our cohort was significantly related to engagement in sexual risk behaviors, which confirms previous research from Uganda (Kibombo et al., 2007; Palomino Gonzáles et al., 2019) showing that knowledge on HIV risk behaviors and awareness of the individual risk it might create is present to some extent.
The main strength of this study is that it explores sexual risk behavior among a large cohort of HIV-negative, pregnant women in a high-prevalence setting in Uganda. As a limitation, we cannot exclude some underreporting of risk behaviors due to social desirability bias, with pregnant women possibly feeling obliged to deny detrimental behavior in front of ANC staff. We tried to mitigate this bias by framing the reporting period as "since the beginning of this year," rather than "during this pregnancy," as pregnant women might have felt enabled to make more open statements through this phrasing. Staff were then probing women's answers with regard to conduct during pregnancy, to avoid capturing prepregnancy behavior. Another limitation is that women in our study might have overreported knowledge of partner status and underreported positive HIV partner status to avoid social stigmatization. Positive partner status might be a significant risk factor for HIV and could influence risk behavior; however, due to suspected underreporting, we did not consider this factor for analysis.

\section{Conclusion}

Our study fills a gap of knowledge on sexual risk behavior during pregnancy by analyzing this behavior within a large cohort of HIV-negative women in Kabarole District, Uganda. One in six women engaged in HIV-specific risk behaviors, and the majority of the women reported to generally abstain from using condoms. Public hospitals, especially in an urban environment, featured clientele with highest rates of risk behaviors. Women's marital and cohabiting status was an important associated factor of risk behavior engagement. Self-estimated individual risk to obtain HIV concurred with engagement in most HIV-specific risk behaviors, but there seems to be a lack of consciousness regarding the effect abusive alcohol consumption can have on sexual health outcomes.

Our findings indicate that HIV prevention in pregnancy is a highly relevant public health concern, and health facilities in settings with high HIV incidence rates should target improved prevention activities at large scale. Individual risk counseling and support should be provided for specific risk groups including women who are widowed, divorced or do not cohabit with their partner. In addition, campaigns to increase awareness on alcohol abuse and the potential danger arising from it, for the fetus but also with respect to HIV infection, are urgently needed.

Acknowledgements The authors thank all participating clients and the staff at the three study facilities in Uganda. The study was funded by the H.W. \& J. Hector Foundation, Germany. 
Funding Open Access funding enabled and organized by Projekt DEAL.

\section{Declarations}

Conflict of interest The authors declare that there are no conflicts of interest.

Ethical Approval The study protocol was approved by the Makerere University School of Public Health Higher Degrees Research and Ethics Committee, by the National Council for Science and Technology in Uganda, and by the Ethics Committee, Charité-Universitätsmedizin Berlin, Germany. All data were treated highly confidential and were only accessible in password-protected files for authorized study staff. Study participation was completely voluntarily and was subject to written informed consent.

Open Access This article is licensed under a Creative Commons Attribution 4.0 International License, which permits use, sharing, adaptation, distribution and reproduction in any medium or format, as long as you give appropriate credit to the original author(s) and the source, provide a link to the Creative Commons licence, and indicate if changes were made. The images or other third party material in this article are included in the article's Creative Commons licence, unless indicated otherwise in a credit line to the material. If material is not included in the article's Creative Commons licence and your intended use is not permitted by statutory regulation or exceeds the permitted use, you will need to obtain permission directly from the copyright holder. To view a copy of this licence, visit http://creativecommons.org/licenses/by/4.0/.

\section{References}

Abimanyi-Ochom, J. (2011). The better the worse: risk factors for HIV infection among women in Kenya and Uganda-Demographic and Health Survey. AIDS Care, 23(12), 1545-1550. https://doi.org/10. 1080/09540121.2011.582477

Corrales-Gutierrez, I., Mendoza, R., Gomez-Baya, D., \& Leon-Larios, F. (2019). Pregnant women's risk perception of the teratogenic effects of alcohol consumption in pregnancy. Journal of Clinical Medicine, 8(6), 907. https://doi.org/10.3390/jcm8060907

Dodoo, F. N., Zulu, E. M., \& Ezeh, A. C. (2007). Urban-rural differences in the socioeconomic deprivation-sexual behavior link in Kenya. Social Science and Medicine, 64(5), 1019-1031.

Drake, A. L., Wagner, A., Richardson, B., \& John-Steward, G. (2014). Incident HIV during pregnancy and postpartum and risk of motherto-child HIV transmission: A systematic review and meta-analysis. PLoS Medicine, 11, e1001608. https://doi.org/10.1371/journal.pmed. 1001608

Fenton, L. (2004). Preventing HIV/AIDS through poverty reduction: The only sustainable solution? The Lancet, 364, 1186-1187.

Gray, R., Li, X., Kigozi, G., Serwadda, D., Brahmbhatt, H., WabwireMangen, F., Nalugoda, F., Kiddugayu, M., Sewenkambo, N., Quin, T. C., Reynolds, S. J., \& Wawer, M. J. (2005). Increased risk of incident HIV during pregnancy in Rakai, Uganda: A prospective study. The Lancet, 366, 1182-1188.

Hong, S. A., \& Thepthien, B. (2017). HIV risk-related sexual behavior by cohabiting partner status among factory workers: Results from the 2015 Bangkok Behavioral Surveillance Survey (BSS). Cogent Social Sciences, 3, 1364070.

Johnson, L. F., Stinson, K., Newell, M.-L., Bland, R. M., Moultrie, H., Davies, M. A., Rehle, T. M., Dorrington, R. E., \& Sherman, G. G. (2012). The contribution of maternal HIV seroconversion during late pregnancy and breastfeeding to mother-to-child transmission of HIV.
Journal of Acquired Immune Deficiency Syndrome, 59(4), 417-425. https://doi.org/10.1097/QAI.0b013e3182432f27

Jones, H. A., Browne, F. A., Myers, B. J., Carney, T., Ellerson, R. M., Kline, T. L., Poulton, W., Zule, W. A., \& Wechsberg, W. M. (2011) Pregnant and nonpregnant women in Cape Town, South Africa: Drug use, sexual behavior, and the need for comprehensive services. International Journal of Pediatrics. https://doi.org/10.1155/2011/353410

Keating, M. A., Hamela, G., Miller, W. C., Moses, A., Hoffman, I. F., \& Hosseinipour, M. C. (2012). High HIV incidence and sexual behavior change among pregnant women in Lilongwe, Malawi: Implications for the risk of HIV acquisition. PLoS ONE, 7(6), e39109. https://doi. org/10.1371/journal.pone.0039109

Kibombo, R., Neema, S., \& Ahmed, F. H. (2007). Perceptions of risk to HIV infection among adolescents in Uganda: Are they related to sexual behaviour? African Journal of Reproductive Health, 11(3), $168-181$

Kinuthia, J., Kiarie, J. N., Farquhar, C., Richardson, B., Nduati, R., Mbori-Ngacha, D., \& John-Stewart, G. (2010). Cofactors for HIV-1 incidence during pregnancy and postpartum period. Current HIV Research, 8, 510-514.

Moodley, D., Esterhuizen, T. M., Pather, T., Chetty, V., \& Ngaleka, L. (2009). High HIV incidence during pregnancy: Compelling reason for repeat HIV testing. AIDS, 23, 1255-1259.

Mpelo, M., Kibusi, S. M., Moshi, F., Nyundo, A., Ntwenya, J. E., \& Mpondo, B. C. T. (2018). Prevalence and factors influencing alcohol use in pregnancy among women attending antenatal care in Dodoma region, Tanzania: A cross-sectional study. Journal of Pregnancy. https://doi.org/10.1155/2018/8580318

Palinkas, L., Horwitz, S. M., Green, C. A., Wisdom, J. P., Duan, N., \& Hoagwood, K. (2015). Purposeful sampling for qualitative data collection and analysis in mixed method implementation research. Administration and Policy in Mental Health and Mental Health Services Research, 42(5), 533-544. https://doi.org/10.1007/ s10488-013-0528-y

Palomino González, R., Kadengye, D. T., \& Mayega, R. W. (2019). The knowledge-risk-behaviour continuum among young Ugandans: What it tells us about SRH/HIV integration. BMC Public Health, 19(Suppl 1), 604. https://doi.org/10.1186/s12889-019-6809-y

Parkhurst, J. O. (2010). Understanding the correlations between wealth, poverty and human immunodeficiency virus infection in African countries. Bulletin of the World Health Organisation, 88, 519-526. https://doi.org/10.2471/BLT.09.070185

Peltzer, K., \& Mlambo, G. (2013). Sexual HIV risk behaviour and associated factors among pregnant women in Mpumalanga South Africa. BMC Pregnancy and Childbirth, 13. https://doi.org/10.1186/ 1471-2393-13-57

Rubaihayo, J., Akib, S., Mughusu, E., \& Abaasa, A. (2010). High HIV prevalence and associated factors in a remote community in the Rwenzori region of Western Uganda. Infectious Disease Reports, 2 , e13. https://doi.org/10.4081/idr.2010.e13

Schnack, A., Rempis, E., Decker, S., Braun, V., Rubaihayo, J., Busingye, P., Tumwesigye, N. B., Harms, G., \& Theuring, S. (2016). Prevention of mother-to-child-transmission of HIV in the Option B+ era: Uptake and adherence during pregnancy in Western Uganda. AIDS Patient Care and STDs, 30,110-118. https://doi.org/10.1089/apc.2015.0318

Schumann, H., Rubagumya, K., Rubaihayo, J., Harms, G., Wanyenze, R., \& Theuring, S. (2020). The incidence of HIV and associated risk factors among pregnant women in Kabarole District, Uganda. PLoS ONE, 15(6), e0234174. https://doi.org/10.1371/journal.pone. 0234174

Shelton, J. D., Cassell, M. M., \& Adetunj, J. (2005). Is poverty or wealth at the root of HIV? The Lancet, 366, 1057-1058.

Tenkorang, E. Y. (2014). Marriage, widowhood, divorce and HIV risks among women in sub-Saharan Africa. International Health, 6, 46-53. https://doi.org/10.1093/inthealth/ihu003 
Uganda AIDS Commission. (2016). The Uganda HIV and AIDS Country Progress Report, July 2015-June 2016. Retrieved from https://www. unaids.org/sites/default/files/country/documents/UGA_2017_count ryreport.pdf

Uganda Bureau of Statistics. (2016). The National Population and Housing Census 2014 Main Report, Kampala, Uganda. https://www.ubos. org/wp-content/uploads/publications/03_20182014_National_Census_Main_Report.pdf

Uganda MoH. (2016). Consolidated guidelines for prevention and treatment of HIV in Uganda. http://library.health.go.ug/publications/hivai ds/consolidated-guidelines-prevention-and-treatment-hiv-uganda

Uganda National Council for Science and Technology. (2014). National guidelines for research involving humans as research participants. Kampala, Uganda. http://mesau.mak.ac.ug/sites/default/ files/Human\%20Subjects\%20Protection\%20Guidelines\%20July\% 202014_0.pdf

UNAIDS. (2020). Fact sheet—World AIDS Day 2020. https://www.unaids. org/sites/default/files/media_asset/UNAIDS_FactSheet_en.pdf
Watt, M. H., Eaton, L. A., Choi, K. W., Velloza, J., Kalichman, S. C., Skinner, D., \& Sikkema, K. J. (2014). "It's better for me to drink, at least the stress is going away": Perspectives on alcohol use during pregnancy among South African women attending drinking establishments. Social Science and Medicine, 116, 119-125. https://doi. org/10.1016/j.socscimed.2014.06.048

WHO. (2010). Delivering HIV test results and messages for re-testing and counselling in adults. http://apps.who.int/iris/bitstream/10665/ 44278/1/9789241599115_eng.pdf

Publisher's Note Springer Nature remains neutral with regard to jurisdictional claims in published maps and institutional affiliations. 